\title{
Functional Impact of Sequence Alterations Found in BRCAl Promoter/5'UTR Region in Breast/Ovarian Cancer Families from Upper Silesia, Poland
}

\author{
Jolanta Pamuła', Małgorzata Krześniak², Helena Zientek', Wioletta Pękala', Marek Rusin², Ewa Grzybowska' \\ Department of Molecular Biology, 2Department of Tumour Biology, Maria Skłodowska-Curie Memorial Cancer Centre and Institute of Oncology, \\ Gliwice Branch, Poland
}

Key words: BRCAl promoter, polymorphism, reporter assay, breast cancer

Corresponding author: Jolanta Pamuła, Department of Molecular Biology, Maria Skłodowska-Curie Memorial Cancer Centre and Institute of Oncology, Gliwice Branch, ul. Wybrzeże Armii Krajowej 15, 44-102 Gliwice, Poland; fax +48 32 2313512; e-mail: ipamula@io.gliwice.pl

Submitted: 4 December 2005

Accepted: 10 January 2006

\begin{abstract}
The $5^{\prime}$ region of $B R C A 1$ contains multiple regulatory sequences flanking the two alternative promoters $\alpha$ and $\beta$ and two alternative, non-coding exons, $1 \mathrm{a}$ and $1 \mathrm{~b}$. Aberrations within the $5^{\prime}$ region BRCA7 (encompassing two alternative promoters $\alpha$ and $\beta$ and exons $1 a$ and $1 b$ ) may be associated with an increased risk of breast and ovarian cancer. In this study we screened 150 patients for polymorphism and mutations in this region of $B R C A 7$. All probands came from familial breast and/or ovarian cancer that had been found to be mutationnegative in a previous search for founder mutations in BRCA1 (185delAG, C61G, 4153delA, 5382insC) or BRCA2 (6174delT, $9631 \mathrm{delC}$ ). In our study we found several sequence alterations within the non-coding region of BRCA7 by using direct DNA sequencing and allele-specific PCR amplification. Three families with a polymorphic deletion in BRCA1 exon $1 \mathrm{~b}$ (2223delAAAAA, Acc. U37574) were found. Moreover, two linked nucleotide substitutions (2642A>T, 2743T>C, Acc. U37574) in BRCA1 intron 1 were detected in 16 patients. In order to assess the functional significance of these two sequence variants, we constructed a reporter vector encoding firefly luciferase under the transcriptional and translational control of wild type and altered BRCA 7 promoter region. The reporter assay was performed using a lung cancer cell line (NCl-H1299) and a breast cancer cell line (MCF7). We have demonstrated that the analysed sequence variants have no functional significance in our experimental system. However, we have found that the BRCA7 promoter has lower relative activity in the breast cancer cell line compared with the lung cancer cell line. Based on the results of our functional experiments we conclude that the polymorphic deletion 2223delAAAAA and two linked substitutions 2642A>T and 2743T>C do not significantly alter BRCA7 expression and are probably not disease-causing mutations.
\end{abstract}

\section{Introduction}

The human BRCA1 gene is under the transcriptional control of two different promoters, $\alpha$ and $\beta$ that drive the transcription of exon $1 \mathrm{a}$ and $1 \mathrm{~b}$, respectively [22].
At the RNA level each of the alternative first exons is linked by splicing with exon 2 [21]. However, the translational initiation site is the same for the two mRNA variants and is located in exon 2 [11]. The BRCA 1 5 'UTR region coded by exon $1 \mathrm{~b}$ contains three 
additional ATG codons upstream of the major translation initiation site [21]. The promoter $\alpha$ is bidirectional and shared with the NBR2 gene $[4,21]$. BRCA 7 contains multiple transcription factor binding sites identified in 5' flanking regions of exon $1 \mathrm{a}$ and exon $1 b[17,18]$. The different transcripts of the BRCA 1 gene are present at different levels in various normal and tumour tissues and may have distinct biological functions [21]. Expression of transcripts $\alpha$ and $\beta$ of the BRCA1 gene may be co-regulated by use of a dual promoter system. Moreover, the two mRNAs may differ in their stability or translational efficiency [21].

Germline mutations within the BRCA1 gene are responsible for familial cancer and reduced expression of the BRCA 1 gene is frequently observed in sporadic breast [12, 16, 20] and ovarian tumours [23]. Various mechanisms such as methylation of the CpG islands within the promoter region $[2,6,10,13]$, allelic deletion of the BRCA 7 locus and sequence alterations identified outside the BRCA 1 coding region, especially within the positive regulatory region (PRR) of the BRCA7 promoter, can modulate the level of BRCA1 expression $[17,19]$. There are also other mechanisms responsible for breast and ovarian cancer pathogenesis [5, 15]. Expression patterns of BRCA 1 mRNAs and differences in their translatability [14] and disruption of the DNAprotein complexes [18] may also contribute to breast/ovarian cancer susceptibility.

Our aim was to investigate the functional effect of sequence alterations within the BRCA 7 promoter $/ 5^{\prime} U T R$ region using luciferase reporter gene assay.

\section{Material and methods}

\section{Patients}

One hundred and fifty patients from families resident in Upper Silesia, Poland, were screened for deletions in the BRCA1 promoter/5'UTR region using genomic DNA extracted from peripheral blood lymphocytes using the phenol-chloroform method [7]. Each patient was selected after clinical genetic counselling in which they completed a detailed questionnaire, including family history, after signing an informed consent document. Each person selected for the study was diagnosed with breast and/or ovarian cancer and had a positive family history of breast and/or ovarian cancer.

\section{Screening for new sequence variants within BRCAI promoter $/ 5^{\prime} U T R$}

Eighty-seven patients diagnosed with breast and/or ovarian cancer were selected for BRCAT
promoter/5'UTR (GenBank accession no. U37574) screening by direct DNA sequencing. All patients were mutation-negative for founder mutations in the BRCA1 gene (185delAG, 300T/G, 4153delA, 5382insC) and in the BRCA2 gene (6174delT, 9631 delC) using ASAPCR and RFLP PCRs analyses [8,9].

PCR amplification was performed using the following primers (forward/reverse, $\left.5^{\prime} \rightarrow 3^{\prime}\right)$ : fragment 1 G A C G C T T G G C T C T T T C T G T /TCTGGATCCTCCTCAAGCAC, fragment 2 GA G T G GA T T T C C GAAG C T GA/ TCTGGACCTCCTCAAGCAC, fragment 3 G A T G G GA C C T T G T G GAA G A A / CGCGAAGAGCAGATAAATCC. All reactions were performed in $15 \mu \mathrm{l}$ containing $1 \mu \mathrm{l}$ 50-150 ng DNA, 1xPCR buffer II (50 mM KCl, 10 mM Tris- $\mathrm{HCl}$ pH 8.3), $1.5 \mathrm{mM} \mathrm{MgCl}, 50 \mathrm{pmol}$ each primer and $1 \mathrm{U}$ of AmpliTaq DNA Polymerase (Applied Biosystem). The PCR cycling conditions were: fragment $1,94^{\circ} \mathrm{C}$ for 30 s, $64^{\circ} \mathrm{C}$ for $30 \mathrm{~s}, 72^{\circ} \mathrm{C}$ for 30 s; fragment $2,94^{\circ} \mathrm{C}$ for 30 s, $59^{\circ} \mathrm{C}$ for $30 \mathrm{~s}, 72^{\circ} \mathrm{C}$ for $30 \mathrm{~s}$; fragment $3,94^{\circ} \mathrm{C}$ for $30 \mathrm{~s}$, $58^{\circ} \mathrm{C}$ for $30 \mathrm{~s}, 72^{\circ} \mathrm{C}$ for $30 \mathrm{~s}$. An initial denaturation for 5 min. at $95^{\circ} \mathrm{C}$ and a final extension at $72^{\circ} \mathrm{C}$ for $7 \mathrm{~min}$. were also included in each $\mathrm{PCR}$ reaction. All reactions were carried out for 35 cycles on a GeneAmpTM PCR System 2400 (Applied Biosystem) thermal cycler. PCR products were separated in a $2 \%$ agarose gel, $1 \times T B E$, stained with ethidium bromide and analysed using Scion Image Beta 4.02 Win Software (Scion Corporation, USA). Amplified products were purified before sequencing with exonuclease I and shrimp alkaline phosphatase according to the manufacturer's protocol (Amersham Life Science). Both strands were sequenced using the following primers $5^{\prime} \rightarrow 3^{\prime}$ : fragment 1 (forward) GACGCTTGGCTCTTTCTGTC, fragment 2 (forward) GTAAGGCGTTGTGAACCCTG and fragment 3 (forward) GGAGACAGGATTTTGTGGGA, fragment 1 (reverse) CAGCCTCCTGAGTAGCTGGA fragment 2 (reverse) TCTGGATCCTCCTCAAGCAC fragment 3 (reverse) CGCGAAGAGCAGATAAATCC. Samples were sequenced with BigDye Terminator Cycle Sequencing Kit v3. 1 (Applied Biosystem) and analysed with the ABI Prism 377 DNA automated sequencer (Applied Biosystem).

Allele-specific PCR amplification was used to estimate the frequency of the polymorphic deletion 2223delAAAAA in an additional sixty-three patients of breast/ovarian cancer patients fulfilling the above criteria. The following primers were used: $\left(5^{\prime} \rightarrow 3^{\prime}\right)$ TTTAAAAACGTCGGCTGGTC (forward), TCCCACAAAATCCTGTCTCC (reverse) and CAGCCGGTGTGTTTTGTTTT (reverse) with 'touch- 
down' PCR: denaturation at $95^{\circ} \mathrm{C}$ for $5 \mathrm{~min}$. followed by 10 cycles of $94^{\circ} \mathrm{C} 20 \mathrm{~s}, 65^{\circ} \mathrm{C} 25 \mathrm{~s}$ (at this point temperature decreased $0.7^{\circ} \mathrm{C}$ per cycle), $72^{\circ} \mathrm{C} 30 \mathrm{~s}$ and followed by 30 cycles at $94^{\circ} \mathrm{C} 20 \mathrm{~s}, 58^{\circ} \mathrm{C} 25 \mathrm{~s}$, $72^{\circ} \mathrm{C} 30$ s ending with a final extension of $72^{\circ} \mathrm{C}$ for 7 min. and a quick chill to $4^{\circ} \mathrm{C}$. PCR reactions were performed in $15 \mu \mathrm{l}$ reactions containing $1 \mu \mathrm{l}$ 50-150 ng DNA, 1xPCR buffer II $(50 \mathrm{mM} \mathrm{KCl}, 10 \mathrm{mM}$ Tris- $\mathrm{HCl}$ $\mathrm{pH}$ 8.3), $1.5 \mathrm{mM} \mathrm{MgCl}, 50 \mathrm{pmol}$ each primer and $1 \mathrm{U}$ of AmpliTaq DNA Polymerase (Applied Biosystem). The PCR product was amplified using a Mastercycler ep ${ }^{\circledR}$

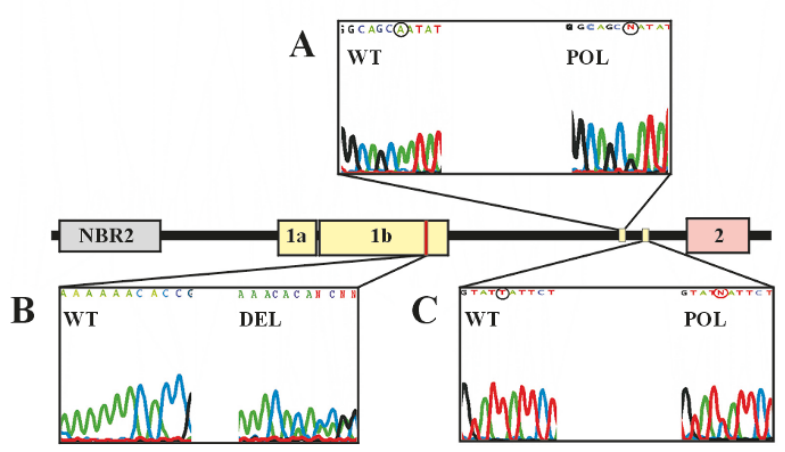

Fig. 1. Schematic representation of the $5^{\prime}$ region of the BRCA1 gene and location of sequence alterations found in this gene fragment$1 \mathrm{a}$ and $1 \mathrm{~b}$ represent two alternative first exons, 2 represents the exon 2 with the translation start site

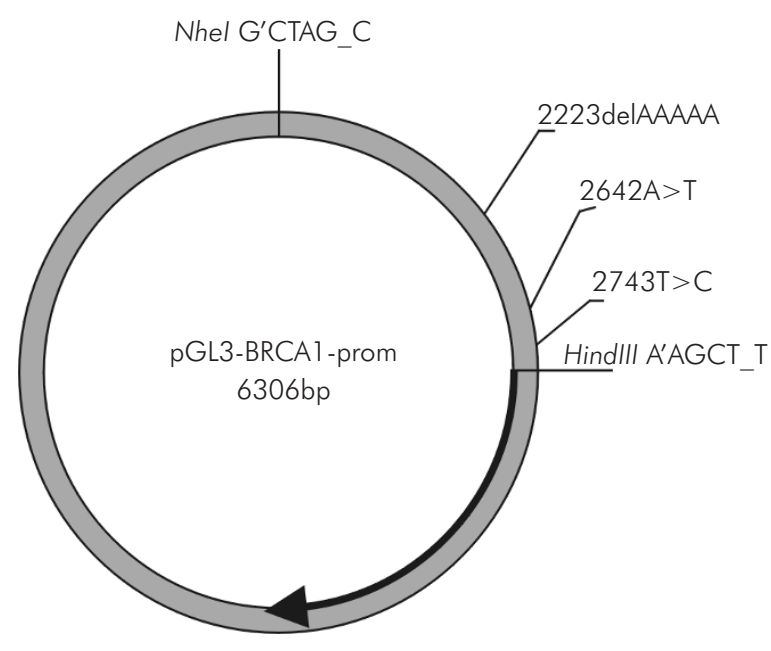

Fig. 2. The pGL3 - BRCA1 - prom plasmid map. The localization of sequence alterations and the recognition sequences of the restriction enzymes used for the cloning are shown. The thick arrow represents the coding region of the firefly luciferase gene (luc) gradient S (Eppendorf) thermal cycler. The amplified products were separated in $2 \%$ agarose gel. The expected size of the PCR fragment containing a polymorphic deletion within exon $1 \mathrm{~b}$ was $261 \mathrm{bp}$.

\section{Functional analyses of region BRCAlpromoter/5'UTR}

Plasmids. The $1.5 \mathrm{~kb}$ DNA region, encompassing minimal BRCA 1 promoter (promoter $\alpha$ ), alternative promoter ( $\beta$ ), exons $1 a, 1 b$ and intron 1 , in wild type and in polymorphic forms, was amplified using the primers 5' $\rightarrow 3^{\prime}$ : TTTTGCTAGCCTTTATGGCAAACTCAGGTAG and TTTTAAGCTTTCTGTTCCAATGAACTTTAAC. The downstream and upstream primers were designed to include Nhel and Hindlll sites, respectively (underlined). The amplified products were digested with Nhel and Hindlll and ligated into pGL3-Basic reporter vector (Promega) digested with Nhel and Hindlll. The pGL3BRCA I-prom plasmids contain the firefly luciferase gene (luc) under the transcriptional and translational control of either the wild type or polymorphic BRCA promoter/5'UTR region (Figure 2). The identity of BRCA1 promoter constructs was confirmed by sequencing. The inserts' nucleotide sequences were compared with the sequence U37574 from GeneBank.

Cell culture, transfection and luciferase assay. Functional analysis of the BRCA 7 promoter/5'UTR region was carried out in human non-small cell lung cancer cell line NCl-H1299 and breast cancer cell line MCF7 (obtained from ATCC). Cells were cultured in DMEM or RPMI-1640 medium (respectively) supplemented with $10 \%$ foetal calf serum and kept at $37^{\circ} \mathrm{C}$ and $5 \% \mathrm{CO}_{2}$. Cell cultures were plated in 12 well culture dishes at 24 hours prior to transfection. At $40 \%$ confluence, lung cancer $\mathrm{NCl}-\mathrm{H} 1299$ and breast cancer MCF7 cells were transfected with $0.5 \mu \mathrm{g}$ DNA of wild type or polymorphic reporter vectors using FuGene6 (Roche) transfection reagent according to the manufacturer's instructions. pRL-TK reporter vector coding for Renilla luciferase (Promega) was cotransfected with $\mathrm{pGL3}$-BRCA1-prom plasmids and served as an internal control. The cells were incubated with FuGene6-DNA for 24 hours. Subsequently the cells were washed in phosphatate buffered saline, lysed in $250 \mu \mathrm{l} 1 \times$ Passive Lysis Buffer and $20 \mu \mathrm{l}$ of the cell lysates were assayed using the Dual-Luciferase Reporter Assay System (Promega). Firefly luciferase activity was divided by Renilla luciferase activity, which yielded normalized firefly luciferase activity. This normalization helps to minimize the confounding influence of differences in cell number, transfection efficiency, etc. Each pGL3-BRCA1-prom plasmid version was 
transfected to the three wells of the 12-well plate. The mean and standard deviation from three luciferase measurements were calculated and the statistical significance of the differences were estimated using the t-test.

\section{Results and discussion}

One hundred and fifty patients with breast and/or ovarian cancer from Upper Silesia in Poland were screened for sequence alterations in the $5^{\prime}$ region of BRCA 1 .

The polymorphic deletion 2223delAAAAA (according to the GeneBank Acc. U37574) within BRCA 1 exon $1 \mathrm{~b}$ was detected in three families (2\%). Two linked nucleotide sequence alterations within the BRCA1 intron $12642 \mathrm{~A}>\mathrm{T}, 2743 \mathrm{~T}>\mathrm{C}$ (Acc. U37574) were also detected in 16 patients (18.4\%) (Figure 1).

The functional impact of the most frequent sequence variants within the $5^{\prime}$ region of BRCA 1 was analysed by the Dual-Luciferase Reporter Assay System (Promega) in the lung cancer cell line (NCl-H1299) and breast cancer cell line (MCF-7). Normalized firefly luciferase activity was significantly lower in the MCF7 cell line compared with the NCl-H1299 cell line (Figure 3).

All tested variants of the BRCA1 promoter/5 'UTR induced expression of the reporter gene at levels very similar to the wild-type sequence in $\mathrm{NCl}-\mathrm{H} 1299$ cell line $(2.15 \pm 0.32$ and $2.02 \pm 0.27$ versus $1.84 \pm 0.123$; $\mathrm{P}=0.19$, $t$-test; Figure 3$)$. The polymorphic sequences slightly reduced expression of reporter luc gene compared with wild-type BRCA1 promoter/5 UTR in MCF7 cell line $(0.51 \pm 0.024$ and $0.55 \pm 0.012$ versus $0.6 \pm 0.07)$; however, the differences were not significant $(P=0.089$, $P=0.263$, $t$-test, respectively; Figure 3$)$. The evidence from this study suggests that the first polymorphism under investigation could only slightly modulate the levels of expression of the BRCA1 gene while the second polymorphism (deletion of 5 nucleotides) did not demonstrate any change in functional activity in the experimental system used in this study.

The $5^{\prime}$ region of $B R C A 1$ contains multiple functional domains which may regulate translation, transcription and alternative splicing of BRCA $[21,22]$. In this study we analysed the BRCA1 5 ' region and detected several sequence alterations. We cloned the region of interest of the BRCA1 gene into the reporter plasmid in order to find out if the sequence alterations modulate the expression of the reporter gene. The deletion of five adenines is a major sequence change. It is located in exon $1 \mathrm{~b}$, which is an alternative exon present in the mRNA mostly in cancer cells $[21,14]$. It may change

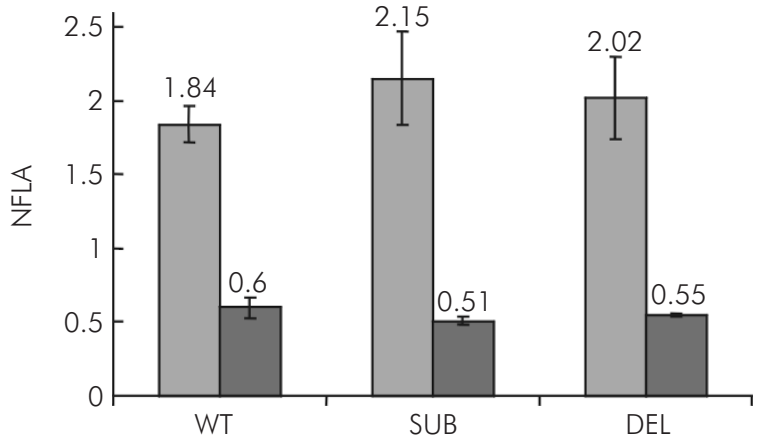

NFLA - normalized firefly luciferase activity

SUB - BRCAl fragment with two linked nucleotide substitutions: $2642 \mathrm{~A}>\mathrm{T}$, $2743 T>C$

DEL - BRCA7 fragment with deletion: 2223delAAAAA

Fig. 3. The normalized activity of the reporter gene (luc) under transcriptional and translational control of the wild-type and polymorphic forms BRCA1 promoter/5'UTR region in $\mathrm{NCl}-\mathrm{H} 1299$ (grey) and MCF7 (dark grey) cell lines

the secondary structure of the 5'UTR of the alternative mRNA, influencing translation efficiency. However, we did not detect its influence on the reporter gene in either of the two cancer cell lines that we used for the assay. The two linked substitutions are located at the $3^{\prime}$ end of intron 1 . In principle, they may modulate the efficiency or accuracy of RNA splicing. However, in the case of these linked sequence changes, we observed no influence on reporter gene expression. Therefore, we conclude that the sequence alterations have no major functional impact on BRCA1 expression. However, we cannot rule out the possibility that they change regulation of BRCA 1 expression in normal cells or when present in their proper chromatin environment.

Interestingly, we noticed that the activity of the reporter gene controlled by BRCA 7 promoter is significantly lower in the MCF7 breast cancer cell line compared with the lung cancer cell line (Fig. 3). Normalized firefly luciferase activity can be regarded as a ratio of experimental promoter activity (BRCA1 in this case) to the control promoter activity (thymidine kinase gene promoter from herpes simplex virus). This ratio is significantly lower in MCF7 cells. This is consistent with the observation of decreased BRCA1 protein level in breast cancer cell lines and primary breast carcinomas associated with the increased expression of negative regulators of $B R C A 1$ promoter [1]. Methylation of the BRCA1 promoter region also decreases the expression level of the protein [3], but this mechanisms is found in a small number of BRCA 1 negative breast cancer specimens [1]. 


\section{Acknowledgements}

We thank Iwona Matuszczyk for excellent technical assistance.

Grant sponsor: State Committee for Scientific Research (KBN, Poland); Grant number 6P05A 14221 (E. Grzybowska)

\section{References}

1. Baldassarre G, Battista S, Belletti B, Thakur S, Pentimalli F, Trapasso F, Fedele M, Pierantoni G, Croce CM and Fusco A. Negative regulation of $B R C A 1$ gene expression by $\mathrm{HMGA} 1$ proteins accounts for the reduced BRCA 1 protein levels in sporadic breast carcinoma. Mol Cell Biol 2003; 23: 2225 2238

2. Baldwin RL, Nemeth E, Tran H, Shvartsman H, Cass I, Narod S and Karlan BY. BRCA1 promoter region hypermethylation in ovarian carcinoma: a population-based study. Cancer Res 2000; 60: 5329-5333.

3. Bianco T, Chenevix-Trench G, Walsh DC, Cooper JE and Dobrovic A. Tumour-specific distribution of BRCA1 promoter region methylation supports a pathogenetic role in breast and ovarian cancer. Carcinogenesis 2000; 21 : 147-151.

4. Brown MA, Xu CF, Nicolai H, Griffiths B, Chambers JA, Black D and Solomon E. The 5 ' end of the BRCA7 gene lies within a duplicated region of human chromosome 17q21. Oncogene 1996; 12: 2507-2513.

5. Brown MA, Lo LJ, Catteau A, Xu CF, Lindeman GJ, Hodgson S and Solomon E. Germline BRCA1 promoter deletions in UK and Australian familial breast cancer patients: Identification of a novel deletion consistent with BRCA1:psiBRCA1 recombination. Hum Mutat 2002; 19: 435-442.

6. Dobrovic A and Simpfendorfer D. Methylation of the BRCA1 gene in sporadic breast cancer. Cancer Res 1997; 57: 33473350

7. Grzybowska E, Hemminki K, Szeliga J and Chorazy M. Seasonal variation of aromatic DNA adducts in human lymphocytes and granulocytes. Carcinogenesis 1993; 14: 2523-2526.

8. Grzybowska E, Zientek H, Jasinska A, Rusin M, Kozlowski P, Sobczak K, Sikorska A, Kwiatkowska E, Gorniak L, Kalinowska E, Utracka-Hutka B, Wloch J, Chmielik E and Krzyzosiak WJ. High frequency of recurrent mutations in BRCA1 and BRCA2 genes in Polish families with breast and ovarian cancer. Hum Mutat 2000; 16: 482-490.

9. Grzybowska E, Sieminska M, Zientek H, Kalinowska E, Michalska J, Utracka-Hutka B, Rogozinska-Szczepka J and KazmierczakMaciejewska M. Germline mutations in the BRCAl gene predisposing to breast and ovarian cancers in Upper Silesia population. Acta Biochem Pol 2002; 49: 351-356.

10. Mancini DN, Rodenhiser DI, Ainsworth PJ, O'Malley FP, Singh SM, Xing W and Archer TK. CpG methylation within the $5^{\prime}$ regulatory region of the $B R C A 7$ gene is tumor specific and includes a putative CREB binding site. Oncogene 1998; 16: $1161-1169$

11. Miki Y, Swensen J, Shattuck-Eidens D, Futreal PA, Harshman K, Tavtigian S, Liu Q, Cochran C, Bennett LM, Ding W, et al. A strong candidate for the breast and ovarian cancer susceptibility gene BRCA1. Science 1994; 266: 66-71.
12. Ozcelik H, To MD, Couture J, Bull SB and Andrulis IL. Preferential allelic expression can lead to reduced expression of BRCA1 in sporadic breast cancers. Int J Cancer 1998; 77: 1-6.

13. Rice JC and Futscher BW. Transcriptional repression of BRCA 1 by aberrant cytosine methylation, histone hypoacetylation and chromatin condensation of the BRCA1 promoter. Nucleic Acids Res 2000; 28: 3233-3239.

14. Sobczak K and Krzyzosiak WJ. Structural determinants of BRCA1 translational regulation. J Biol Chem 2002; 277: 17349-17358.

15. Signori E, Bagni C, Papa S, Primerano B, Rinaldi M, Amaldi F and Fazio VM. A somatic mutation in the 5'UTR of BRCA1 gene in sporadic breast cancer causes down-modulation of translation efficiency. Oncogene 2001; 20: 4596-4600.

16. Sourvinos $G$ and Spandidos DA. Decreased BRCA1 expression levels may arrest the cell cycle through activation of p53 checkpoint in human sporadic breast tumors. Biochem Biophys Res Commun 1998; 245: 75-80.

17. Suen TC and Goss PE. Transcription of BRCA1 is dependent on the formation of a specific protein-DNA complex on the minimal BRCA7 Bi-directional promoter. J Biol Chem 1999; 274: 31297 31304.

18. Thakur S and Croce CM. Positive regulation of the BRCA1 promoter. J Biol Chem 1999; 274: 8837-8843.

19. Thakur S, Nakamura T, Calin G, Russo A, Tamburrino JF, Shimizu M, Baldassarre G, Battista S, Fusco A, Wassell RP, Dubois G, Alder $\mathrm{H}$ and Croce CM. Regulation of BRCA 1 transcription by specific single-stranded DNA binding factors. Mol Cell Biol 2003; 23: 3774-3787.

20. Thompson ME, Jensen RA, Obermiller PS, Page DL and Holt JT. Decreased expression of BRCA1 accelerates growth and is often present during sporadic breast cancer progression. Nat Genet 1995; 9: 444-450.

21. Xu CF, Brown MA, Chambers JA, Griffiths B, Nicolai H and Solomon $E$. Distinct transcription start sites generate two forms of BRCA1 mRNA. Hum Mol Genet 1995; 4: 2259-2264.

22. Xu CF, Chambers JA and Solomon E. Complex regulation of the BRCA1 gene. J Biol Chem 1997; 272: 20994-20997.

23. Zheng W, Luo F, Lu JJ, Baltayan A, Press MF, Zhang ZF, Pike MC. Reduction of BRCA1 expression in sporadic ovarian cancer. Gynecol Oncol 2000; 76: 294-300. 